\title{
Impact of Land Use and Land Cover Changes in the Surface Fluxes of an Atmospheric Model
}

\author{
Valentine G. Anantharaj, Patrick J. Fitzpatrick, Yongzuo Li, Roger L. King, and Gueorgui V. Mostovoy \\ GeoResources Institute \\ Mississippi State University \\ Mississippi State, MS 39762-9627, USA \\ val@gri.msstate.edu
}

\begin{abstract}
High resolution numerical weather prediction models are sensitive to changes in the prescribed land use data. The land use and land cover (LULC) information, derived from NASA's Moderate Resolution Imaging Spectroradiometer (MODIS) sensors, has been substituted for the Global Land Cover Characterization (GLCC) land use data based on 1-km AVHRR observations in the Coupled Ocean Atmosphere Mesoscale Prediction System (COAMPS), a NWP model developed by the U. S. Navy. The changes in the model ground wetness, due to the prescription of different LULC information, affect the distribution of convective cells and the pattern of rainfall. The temperature fields at and near the surface show greater variability when MODIS land cover data are prescribed. The surface temperatures are higher in the north western portion of the domain but lower in the south eastern coastal regions of Louisiana. Changes in ground wetness due to land cover changes impact the surface temperatures more than changes in albedo or surface roughness. The differences in latent heat fluxes were noticeable in increased urbanized areas around the cities New Orleans and Mobile. The land cover changes also resulted in different patterns of thunderstorm formations.
\end{abstract}

Keywords- AVHRR; COAMPS; MODIS; landuse; landcover; land surface parameterization; energy fluxes

\section{INTRODUCTION}

The earth's atmosphere constantly interacts with the land and ocean surfaces- exchanging energy and moisture via the boundary layer at the atmosphere and land/ocean interface. The land surface processes, represented in numerical models, impact the weather and climate predictions over a range of spatial and temporal scales [1]. Changes in soil and vegetation dynamics affect the moisture and energy fluxes across the landatmosphere interface and influence convective rainfall [2]. The land-atmosphere interactions govern the partitioning of the energy, moisture, and momentum fluxes into sensible and latent heat fluxes, the evaporation and transpiration of moisture, and characterize the surface and boundary layer winds. The land surface conditions are represented via the surface parameters of soil moisture, albedo, and terrain roughness. These critical processes are resolved in numerical weather prediction models via sophisticated land surface models (LSM) or proper land surface parameterization (LSP) schemes.

\section{A. COAMPS}

The Coupled Ocean/Atmosphere Prediction System (COAMPS), developed at the Naval Research Laboratory, includes a meteorological model that is used by the U.S. Navy to provide operational forecasts for different regions around the world [3]. WorldWinds Inc., a private company, uses COAMPS to produce weather forecast products in support of marine, oil and gas, aviation, agriculture, emergency management, and insurance industries. The Mississippi State University / GeoResources Institute also routinely runs COAMPS for research studies and applications. COAMPS uses a straight forward land surface parameterization technique that is intended to be computationally efficient. This scheme uses a land use and land cover (LULC) database to match the associated land cover type(s) for each model grid cell, and then uses a lookup table to extract and interpolate the values of the necessary land surface parameters, namely surface albedo, ground wetness, and roughness length [4].

\section{LANDUSE LANDCOVER DATA SETS}

\section{A. The USGS GLCC Data}

The atmospheric model in COAMPS uses a simplified land surface parameterization scheme where land use and land cover (LULC) classes are used as surrogates to derive climatological values of the surface parameters albedo, surface roughness, and ground wetness. The 1-km high resolution Global Land cover Characteristics (GLCC) data used by COAMPS are derived from multitemporal AVHRR observations for the 12-month period of April 1992 - March 1993 [5,6] in support of the International Geosphere Biosphere Programme (IGBP). The classification methodology involved the application of unsupervised classification techniques to monthly composites of multitemporal Normalized Difference Vegetation Index (NDVI) data. The clusters identified during the classification process are labeled, stratified, and further aggregated to derive seven separate LULC data sets based on different classification schemes, including the Olson Global Ecosystems Framework (OGEF) that consists of 94 ecosystems classes and the IGBP DISCover consisting of 17 classes. 


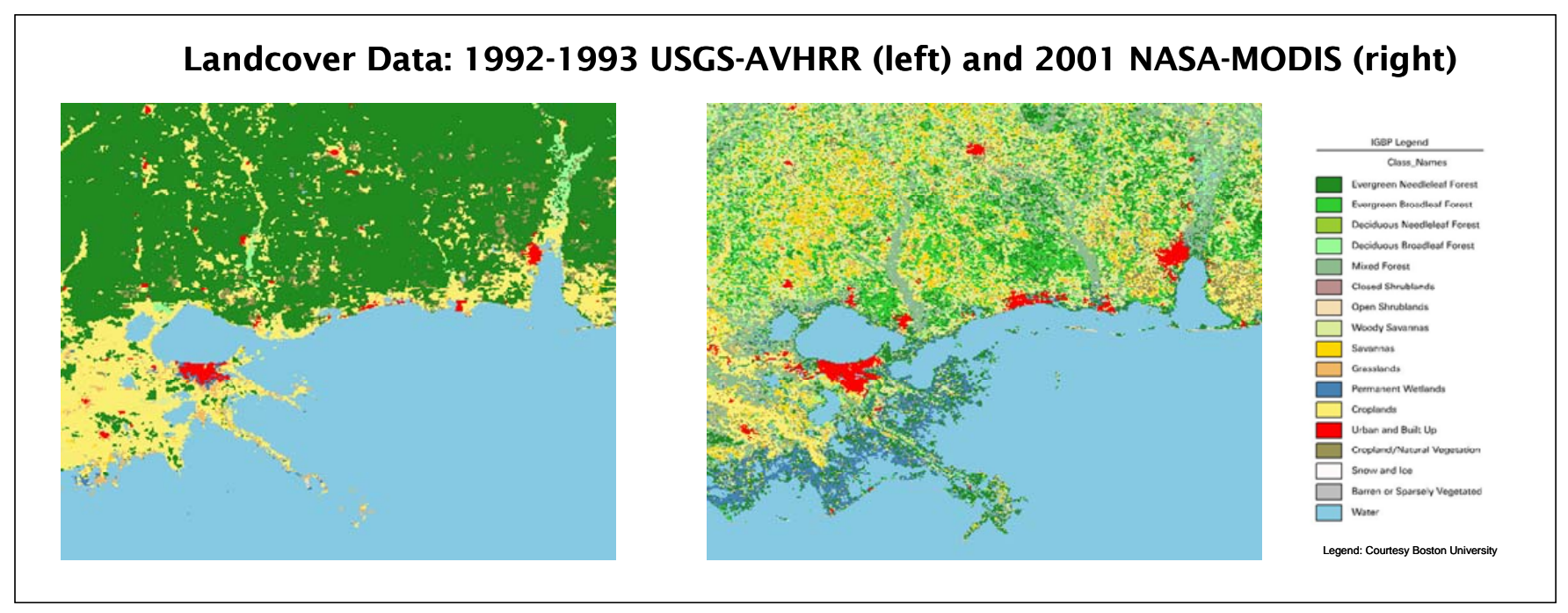

Figure 1. The USGS GLCC data (left) and the MODIS derived land cover data (right) for the 3-km domain.

\section{B. The MODIS Landcover Data}

The MODIS Land Cover product MOD12Q1 Version 004 $[7,8]$ was obtained from Boston University. The land cover data are derived from MODIS Level 2 and 3 products using decision tree classification techniques with boosting $[9,10]$. The data set was based on a nominal day 2001001 for the period 1 January 2001 - 31 December 2001. The 17-category IGBP land cover data were adopted for application in COAMPS. The IGBP Class \#13, Urban and Built-up, was not included in this data. Instead, a rasterized Digital Chart of the World was overlaid for this category [9].

\section{DATA PROCESSING AND ANALYSIS}

\section{A. Methodology}

The USGS GLCC data used by COAMPS uses the 94 category OGEF scheme. However, the MODIS derived LULC data are not available as OGEF classes; but both sources of data are available in the 17-category IGBP scheme. Hence, a methodology was developed to "cross-walk" the OGEF classes to the IGBP classes. Since the USGS GLCC data were available in both OGEF and IGBP schemes, a simple twodimensional histogram was computed to derive the percentage of OGEF classes that contribute to the individual IGBP classes in a spatial domain, nearly corresponding to the $27-\mathrm{km}$ nest of the model, along the Louisiana- Mississippi-Alabama Gulf Coast region. The four most prominent IGBP classes, namely Evergreen Needleleaf Forest, Croplands, Cropland / Natural Vegetation Mosaic, and Deciduous Broadleaf Forest, account for nearly $97 \%$ of all land cover in the domain [11]. Further, these four dominant classes cross-walked to at most three OGEF classes each to account for the at least $90 \%$ of the distribution of the respective IGBP classes. A new set of climatological values of albedo, surface roughness, and ground wetness were computed for the IGBP scheme and implemented in COAMPS atmospheric model.

\section{B. Comparisons}

The GLCC and MODIS land cover information are shown in Fig. 1 for the 3-km model domain. The coverage of the categories in the GLCC data is more or less homogeneous whereas the MODIS data show a contrasting mixture and a grainy pattern. The urban areas have a better representation in the MODIS data showing more coverage in the New Orleans and Mobile metro areas, along the Mississippi Gulf Coast, and the suburban areas north of Lake Pontchartrain.

The land cover in the south eastern Louisiana is mostly permanent wetlands that are fast disappearing due to subsidence. The GLCC data, though representative of an earlier time period than the MODIS data, do not contain most of these wetlands. Though the wetlands are characterized with fair coverage, they are misrepresented in the SE Louisiana. Much of the wetlands in this region are categorized as one of the forest categories. This problem has not been corrected for the initial set of modeling experiments. Efforts are in progress to rectify the incorrect pixels and run the model again.

A confusion matrix was derived for the AOI to map the distribution the 94 classes from the Olson scheme across the 17 IGBP classes. Weighing coefficients were then derived based on the distribution of the 17 USGS IGBP classes across the 94 USGS OGEF classes. Based on these results, a methodology has been developed to optimally derive climatological estimates of albedo, ground wetness, and surface roughness length parameters used by COAMPS. The climatological values for the 17 IGBP classes were computed by multiplying the OGEF coefficients by their corresponding weights and then adding up. Three of the IGBP classes could not be mapped to any of the OGEF classes due to the limited model domain. However, this fact does not affect the model computations for our AOI. But if the model were to be reconfigured for a different domain, a new set of climatological coefficients will have to be derived based on the AOI. 

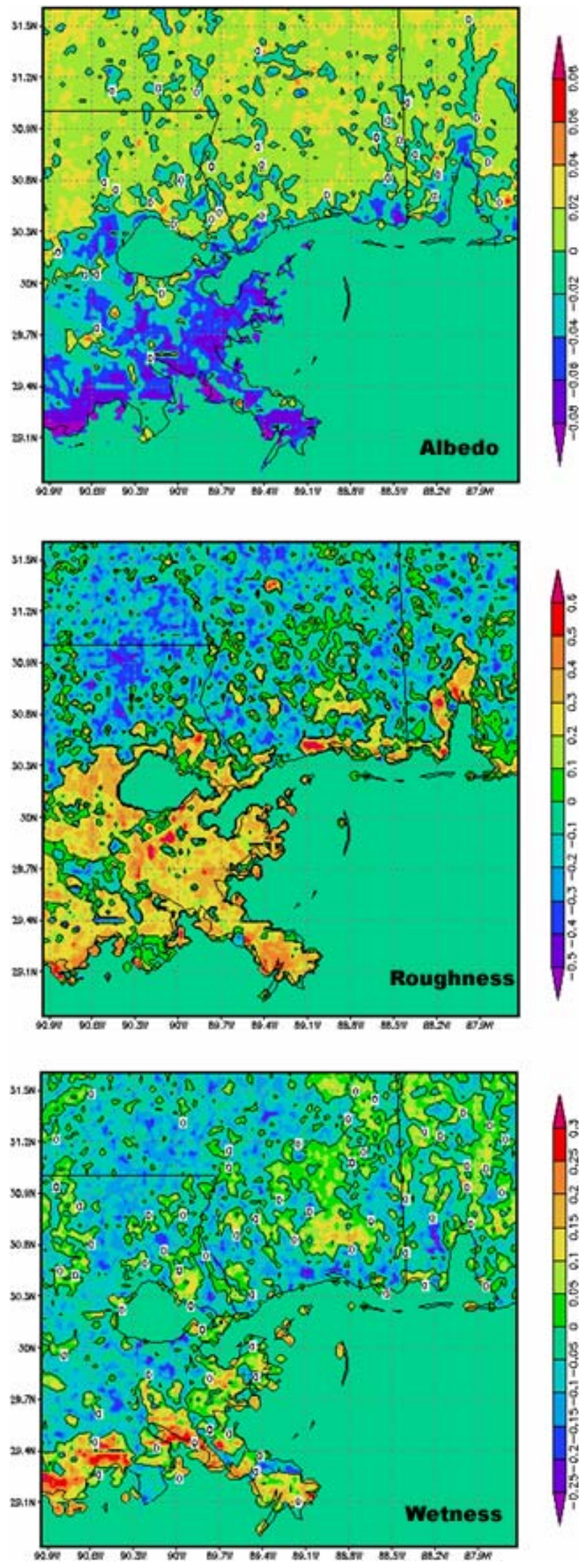

Figure 2. Differences between MODIS and USGS GLCC derived initial fields (MODIS -GLCC) of albedo (top), surface roughness (middle) and ground wetness (bottom) for the 3-km domain.

\section{EXPERIMENTS AND ANALYSIS}

\section{A. Model and Domain Configuration}

The COAMPS model, Version 3.1, was configured in four nested domains of $27,9,3$, and $1 \mathrm{~km}$ spatial resolutions. The grid dimensions for the nests were $61 \times 51,79 \times 73,127 \times 121$, and $247 x 235$ grid points respectively. The model was first run in cold-start mode for the first 12 hours starting at 8 June 2004, 00 UTC. It was then initialized with data assimilation at 1200 UTC and run for 36 forecast hours. The model was run with (a) the default 1-km land use database from United States Geological Survey (USGS) based on the 1992 Advanced Very High Resolution Radiometer (AVHRR) data, and (b) with a recent 2000 land use classification data from the Moderate Resolution Imaging Spectroradiometer (MODIS) operated by the National Aeronautics and Space Administration (NASA).

The model was run on a SGI Origin 2000 computer using 24 processors. The 4 nests run with 1-km inner nest runs require approximately 3.5 hours of wall clock time for every forecast hour. The 3 nest runs with $3-\mathrm{km}$ inner nest requires only 30 minutes of wall clock time for every forecast hour. The results from the $3-\mathrm{km}$ nests are shown in the figures and discussed here

\section{PRELIMINARY ReSUlts AND Discussion}

Two sets of experiments were done, first with the USGS GLCC land cover prescription and the other with MODIS land cover. The model generates slightly different initial fields of albedo, ground wetness, and surface roughness in each case (Fig. 2). The MODIS derived albedo has slightly higher values in the northern half of the 3-km domain and lower values in the south western quadrant. The surface roughness values are higher in the SW quadrant and slightly lower in the northern half for the MODIS case and more or less lower elsewhere. The urban and built-up areas also show higher values of surface roughness. Initial ground wetness is higher along the SE Louisiana coast for the MODIS case.

The coastal region along Gulf of Mexico in our domain was dominated by a fair weather high pressure system on June 9, 2004, characterized by mostly south easterly wind flow. Though there was a little thunderstorm activity in the domain, but it was relatively moderate. The sea breeze was embedded in the ambient flow, and the propagation of the sea breeze front though evident in the model forecasts, was not sharply defined.

The prescription of the MODIS land cover data resulted in higher temperatures at and near the surface layers in the north western quadrant of the $3-\mathrm{km}$ domain during the daytime (Fig. 3) where as the temperatures lower in the north eastern quadrant and the south eastern coastal areas of Louisiana. The coastal areas in Mississippi also had higher day time temperatures, and the heat island effect was more pronounced in the New Orleans metropolitan region. The different ground wetness conditions due to land cover changes have a bigger impact on day time surface temperature differences than differences in albedo or surface roughness.

The surface roughness lengths in SE Louisiana generally increased when MODIS land cover data were applied. The 

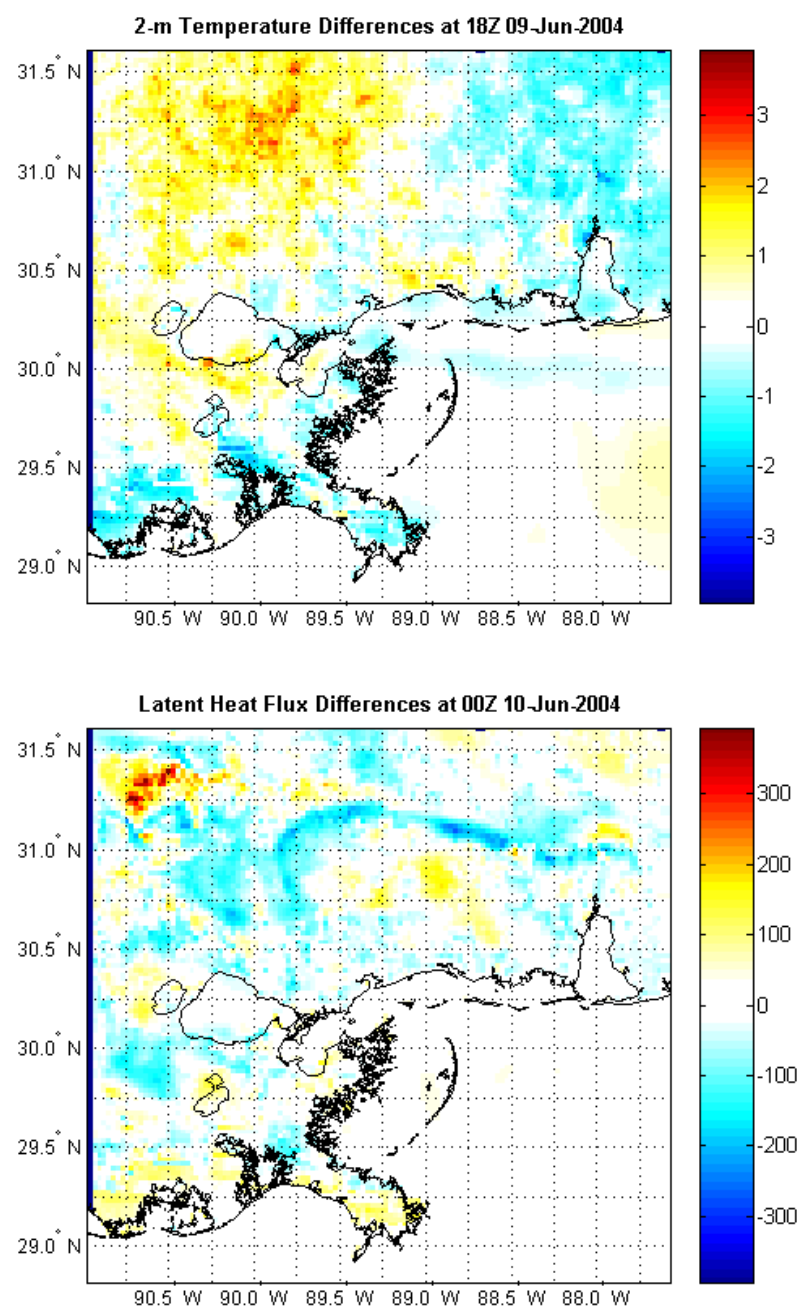

Figure 3: (MODIS - USGS) 2-m temperature differences (top) and latent heat fluxes (bottom), valid at 00Z June 9.

decrease in wind speeds. However, along the Mississippi coast, there was no clear pattern in the wind speed differences. Hence, no clear determination could be made about the differences due to these land cover changes in the genesis and propagation of sea breeze along the Mississippi Gulf coast on June 9. The different temperature patterns as well as the surface roughness lengths may need to be considered to account for the differences in wind patterns.

The changes in the land cover altered the surface fluxes, particularly the latent heat fluxes. The changes were more evident in the urban and built up areas of the MODIS data
(Fig. 3). Prominent changes can also be noticed along the sea breeze frontal zone where the USGS results show increased latent heat fluxes. The thunderstorm formation - location and distribution - were also a little different between the runs. The distribution of the 12-hour accumulated precipitation (Fig. 6) compare reasonably well qualitatively with observations (not shown) in both instances of the model runs. Further diagnostics are necessary to understand and evaluate the impacts due to changes in radiation. More detailed analysis of energy budgets are also in progress.

\section{ACKNOWLEDGMENT}

The authors of this paper would like to acknowledge NASA for its funding of this research through NAG1303012 via the Enterprise for Innovative Geospatial Systems.

\section{REFERENCES}

[1] Betts, A., J. H. Ball, A. C. Beljaars, M. J. Miller, and P. A. Viterbo, 1996: The land surface-atmosphere interaction: A review based on observational and global modeling perspectives. J. of Geophy. Res., 101, D3, 7209-7225.

[2] Pielke, R., A. (Sr), 2001: Influence of the Spatial Distribution of Vegetation and Soils on the Prediction of Cumulus Convective Rainfall. Rev. of Geophy., 39, 151-177.

[3] Hodur, R. M., 1997: The Naval Research Laboratory's Coupled Ocean/Atmosphere Mesoscale Prediction System. Mon. Wea. Rev., 125, 1414-1430.

[4] The COAMPS Training and Workshop Manual, 2002: Naval Research Laboratory, 4-6 September 2002, Monterey, California.

[5] USGS: Global Land Cover Characterization. http://edcdaac.usgs.gov/glcc/glcc.asp

[6] Loveland, T. R., B. C. Reed, J. F. Brown, D. O. Ohlen, Z. Zhu, Y. Yang, and J. W. Merchant, 2000: Development of a global land cover characteristics database and IGBP DISCover from $1 \mathrm{~km}$ AVHRR data. Int. J. of Rem. Sens., 21, 1303-1330.

[7] Justice, C. O., E. Vermote, J. R. Townsend, R. Defries, D. P. Roy, D. K. Hall, V. V. Solomonson, J. L. Privette, G. Riggs, A. Strahler, W. Lucht, R. B. Myneni, Y. Knyazikhin, S. W. Running, R. R. Nemani, Z. Wan, A. R. Huete, W. van Leeuwen, R. E. Wolfe, L. Giglio, J-P. Muller, P. Lewis, and M. J. Barnsley, 1998: The Moderate Resolution Imaging Spectroradiometer (M ODIS): Land Remote Sensing for Global Change Research. IEEE Trans. of Geosci. and Rem. Sens., 36, 1228-1249.

[8] Masuoka, E., A. Fleig, R. E. Wolfe, and F. Patt, 1998: Key Characteristics of MODIS Data Products. IEEE Trans. of Geosci. and Rem. Sens., 36, 1313-1323.

[9] Boston University, 2003: MODIS MOD12 Landcover and Land Dynamics Products User Guide. http://geography.bu.edu/landcover/userguidelc/lc.html

[10] Strahler, A., D. Muchoney, J. Borak, M. Friedl, S. Gopal, E. Lambin, and A. Moody, 1999: MODIS Land Cover Product Algorithm Theoretical Basis Document, Version 5.0. Boston University.

[11] Anantharaj, V. G., P. J. Fitzpatrick, R. L. King, and L. Wasson, 2004: Incorporation of MODIS land cover data to improve land surface parameterization in the COAMPS numerical weather prediction model. Proc. of the IEEE Int. Geosci. And Rem. Sens. Symp., 20-24 September 2004, Anchorage, AK. 